\title{
Numerical and analytical investigation of compressional wave propagation in saturated soils
}

\author{
Bo Han, Lidija Zdravković, Stavroula Kontoe \\ Department of Civil \& Environmental Engineering, Imperial College, London SW7 2AZ, United Kingdom
}

\begin{abstract}
In geotechnical earthquake engineering, wave propagation plays a fundamental role in engineering applications related to the dynamic response of geotechnical structures and to site response analysis. However, current engineering practice is primarily concentrated on the investigation of shear wave propagation and the corresponding site response only to the horizontal components of the ground motion. Due to the repeated recent observations of strong vertical ground motions and compressional damage of engineering structures, there is an increasing need to carry out a comprehensive investigation of vertical site response and the associated compressional wave propagation, particularly when performing the seismic design for critical structures (e.g. nuclear power plants and high dams). Therefore, in this paper, the compressional wave propagation mechanism in saturated soils is investigated by employing hydro-mechanically (HM) coupled analytical and numerical methods. A HM analytical solution for compressional wave propagation is first studied based on Biot's theory, which shows the existence of two types of compressional waves (fast and slow waves) and indicates that their characteristics (i.e. wave dispersion and attenuation) are highly dependent on some key geotechnical and seismic parameters (i.e. the permeability, soil stiffness and loading frequency). The subsequent HM Finite Element (FE) study reproduces the duality of compressional waves and identifies the dominant permeability ranges for the existence of the two waves. In particular the existence of the slow compression wave is observed for a range of permeability and loading frequency that is relevant for geotechnical earthquake engineering applications. In order to account for the effects of soil permeability on compressional dynamic soil behaviour and soil properties (i.e. P-wave velocities and damping ratios), the coupled consolidation analysis is therefore recommended as the only tool capable of accurately simulating the dynamic response of geotechnical structures to vertical ground motion at intermediate transient states between undrained and drained conditions.
\end{abstract}


Key Words: hydro-mechanically coupling, compressional wave propagation, analytical solution, finite element analysis, vertical site response

\section{Introduction}

\subsection{Background}

During an earthquake, the ground is subjected to simultaneous shaking in both the horizontal and vertical directions. However, it is common practice for geotechnical earthquake engineering problems to investigate the vertically propagating shear waves and assess the corresponding site response only to the horizontal components of the ground motion. This is based on the assumption that the effect of the vertical component of the ground motion, induced predominantly by vertically propagating compressional waves, is less significant, due to its smaller magnitude and higher frequency content compared to the horizontal ground motion component (Yang and Yan, 2009). However, since 1990s, strong vertical ground motions have been repeatedly observed, leading to significant damage of engineering structures in the form of vertical compression (Papazoglou and Elnashai, 1996; Yang and Sato, 2000; Bradley, 2011; Lee et al., 2013; Riches, 2015). In particular in the recent 2011 Christchurch earthquake, strong vertical ground motions were widely observed (Lee et al., 2013), which induced significant damage on crib retaining walls due to the contact loss of the crib units in the vertical direction (Riches, 2015). Furthermore, the numerical investigations of the response of structures described in Kunnath et al. (2008), show that neglecting the vertical ground motions in the seismic design of highway bridges and overcrossings may lead to failures due to bending moment capacity exceedance induced by strong vertical motions. Moreover, for the seismic design of critical structures (e.g. nuclear power plants, high dams), ground motion effects have to be taken into account for a very wide frequency range, with the compressional waves usually dominating the high-frequency limit. There is therefore a need for a more rigorous investigation of compressional wave propagation in geotechnical materials, which will ultimately assist the development of a better understanding of the site response due to vertical ground motion. In this paper, the compressional wave propagation mechanism in saturated soils is investigated, by employing a hydro-mechanically (HM) coupled analytical solution and an HM coupled Finite Element (FE) method. An analytical solution for compressional wave 
propagation, which is based on Biot's theory (1956a, b), is firstly employed to investigate the characteristics of the two types of compressional waves (fast and slow waves). The subsequent HM FE study reproduces the duality of compressional waves and identifies the dominant permeability ranges for the existence of the two waves. The predicted characteristics of the compressional waves (i.e. wave dispersion and attenuation) in different frequency ranges are further compared against the analytical solution to investigate the significance of the two types of waves in different conditions (i.e. undrained, drained or intermediate states).

\subsection{Compressional wave propagation in saturated porous materials}

The undrained approximation is a common assumption for analysing geotechnical earthquake engineering problems, which is of acceptable accuracy for relatively impermeable materials or/and under loading of relatively short duration. However, due to the complexity of dynamic soil behaviour and earthquake loading conditions, consolidation can occur in a soil profile during seismic loading, depending on the range of the dynamic loading duration and soil permeability. In that case, the undrained solution is insufficient for the accurate simulation of dynamic soil behaviour and a HM coupled analysis, which accounts for soil-pore fluid interaction effects, is required to investigate the seismic wave propagation mechanism.

The HM coupled theory concerning the elastic wave propagation in saturated porous materials was initially studied by Biot (1956a, b). Based on the proposed formulation, three types of waves are introduced in saturated soil media under dynamic loading; two types of compressional waves and one type of shear wave. The two compressional waves are known as the fast wave and slow wave. In particular, the fast wave exists when the pore fluid and solid particles move in-phase under dynamic loading, while the slow wave is generated when there is an out-of-phase movement between pore fluid and solid phase (as shown in Figure 1). It was pointed out by Biot (1956a) that the fast wave is the usually observed compressional body wave in earthquake engineering, known as a P-wave. On the other hand, the slow wave is highly dispersive and tends to attenuate at low loading frequencies and low permeabilities. 


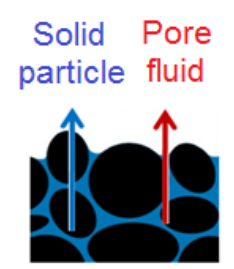

Low $\mathrm{k}$

Fast wave
Solid Pore particle fluid

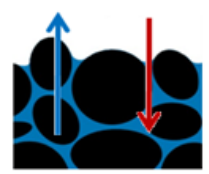

High $\mathrm{k}$

Slow wave

Figure 1: A schematic graph for the fast and slow wave

Since 1956, when the HM coupled dynamic theory of elastic wave propagation in saturated porous materials was proposed by Biot, the existence of the slow wave has been widely doubted by researchers. It was only in 1980, when Plona (1980) proved experimentally for the first time the existence of slow waves propagating in saturated porous materials (using sintered glass spheres saturated with water). It should be noted that the material was subjected to an ultrasonic-frequency load (greater than $2000 \mathrm{~Hz}$ ), in order to trigger the development of slow waves. After Plona (1980), researchers started to extensively investigate the existence of the slow wave. Rasolofosaon (1988) modified Plona's device and observed the slow wave in water-saturated porous plates made of artificially bonded natural sand grains. Nagy (1990) carried out similar experiments and observed the slow wave in natural rocks, which was the first time that the slow wave was experimentally observed in a natural material.

Apart from the experimental work, efforts were also dedicated to the analytical investigation of the compressional wave propagation. Dutta (1980) and Berryman (1980) compared the observed slow wave velocities from Plona's work (1980) with the analytical expressions of the compressional wave velocities derived from Biot's theory (1956a, b) and showed a good agreement. Boyle and Chotiros (1991) carried out experiments with samples made of river sediments and observed the slow wave under ultrasonic-frequency loading. The observed slow wave velocities were compared with Biot's analytical expressions for the compressional wave velocities and showed some discrepancy. This was attributed to possible inaccuracies in the estimation of the bulk modulus of the solid skeleton.

Teng (1990), probably for the first time, employed the FE method to investigate the slow wave propagation in porous materials subjected to ultrasonic-frequency loading, by simulating Plona's (1980) experiment. Gurevich et al. (1999) also successfully 
validated Biot's slow wave theory by simulating Plona (1980) experimental work employing his OASES FE modelling code. Furthermore, Arntsen and Carcione (2001) numerically proved the existence of the slow wave in water-saturated Nivelsteiner sandstone under ultrasonic-frequency loading by employing the finite difference method. Their results compared well with the experimental observations presented by Kelder and Smeulders (1997), where a test similar to Plona (1980) work was carried out. The discrete element method (e.g. Gu and Zhao (2009), Wu (2010)) has also been employed to investigate the compressional wave propagation in rock materials associated with slope failures. However, these studies concentrate on the investigation of the fast waves without accounting for the HM behaviour of saturated porous materials.

Clearly, the vast majority of the presented existing studies concentrated on the investigation of the existence of the slow wave under the ultrasonic-frequency loading. This is because the slow wave is less dispersive and is not significantly attenuated under high frequency loading and therefore it becomes easier to observe. Nevertheless, the ultrasonic-frequency loading is beyond the relevant frequency range for geotechnical earthquake engineering problems. However, according to Biot (1956a) and Kim et al. (2002), the dispersion and attenuation characteristics of the fast and slow waves do not only depend on the loading frequency range, but are also affected by the examined soil permeability range. More importantly, the impact of the permeability on the characteristics of the compressional waves in geotechnical materials can be more significant than that of the loading frequency. Therefore, this study focuses on the investigation of the permeability effect on the compressional wave propagation mechanism, by employing a HM coupled analytical theory and numerical analysis.

\section{Analytical investigation of compressional wave propagation in saturated soils}

In this section, a HM coupled analytical solution for the compressional wave propagation is studied. In particular, firstly, the HM coupled governing equation of motion for saturated porous materials is reviewed based on Biot's theory (1956a, b). Furthermore, by combining the elastic wave propagation equation with the coupled governing equation of motion, the exact solutions for the dispersion and attenuation 
characteristics of compressional waves are derived. Finally, based on the derived solution, the characteristics of the compressional waves are parametrically investigated.

\subsection{HM coupled governing equation of motion}

Based on Biot (1956a) and Bardet and Sayed (1993), the one-dimensional dynamic response of saturated porous visco-elastic materials can be described by Equation (1).

$$
\left\{\begin{array}{l}
\left(D+\frac{1-n}{n} \cdot K_{f}\right) \cdot \frac{\partial^{2} v_{s}}{\partial z^{2}}+K_{f} \cdot \frac{\partial^{2} v_{f}}{\partial z^{2}}=(1-n) \cdot \rho_{s} \cdot \frac{\partial^{2} v_{s}}{\partial t^{2}}+n \cdot \rho_{f} \cdot \frac{\partial^{2} v_{f}}{\partial t^{2}} \\
K_{f} \cdot\left(\frac{1-n}{n} \cdot \frac{\partial^{2} v_{s}}{\partial z^{2}}+\frac{\partial^{2} v_{f}}{\partial z^{2}}\right)=n \cdot \rho_{f} \cdot \frac{\partial^{2} v_{f}}{\partial t^{2}}+\frac{n \cdot \rho_{f} \cdot g}{k} \cdot\left(\frac{\partial v_{f}}{\partial t}-\frac{\partial v_{s}}{\partial t}\right)
\end{array}\right.
$$

where $v_{s}$ and $v_{f}, \rho_{s}$ and $\rho_{f}$ are the vertical displacements and densities of the solid skeleton and pore fluid respectively, $D$ is the soil skeleton constrained modulus, which can be converted from the Young's modulus $(E)$ and Poisson's ratio (v) (i.e. $\left.D=\frac{E \cdot(1-v)}{(1+v) \cdot(1-2 v)}\right), K_{f}$ is the pore fluid bulk modulus (approximately 2.2E6 kPa for water under the atmospheric pressure of $100 \mathrm{kPa}$ ), $n$ and $k$ are the material porosity and permeability respectively, $g$ is the gravitational acceleration and $z$ is the space variable in the vertical direction.

After rearrangement, Equation (1) becomes:

$$
\left\{\begin{array}{l}
c_{w}^{2} \cdot\left(\left(\frac{1}{n}+\chi\right) \cdot \frac{\partial^{2} v_{s}}{\partial z^{2}}+\frac{1}{n} \cdot \frac{\partial^{2} v_{r}}{\partial z^{2}}\right)=\frac{1}{\beta} \cdot \frac{\partial^{2} v_{s}}{\partial t^{2}}+\frac{\partial^{2} v_{r}}{\partial t^{2}} \\
c_{w}^{2} \cdot\left(\frac{1}{n} \cdot \frac{\partial^{2} v_{s}}{\partial z^{2}}+\frac{1}{n} \cdot \frac{\partial^{2} v_{r}}{\partial z^{2}}\right)=n \cdot \frac{\partial^{2} v_{s}}{\partial t^{2}}+\frac{\partial^{2} v_{r}}{\partial t^{2}}+\frac{g}{k} \cdot \frac{\partial v_{r}}{\partial t}
\end{array}\right.
$$

where the relative vertical displacement between the solid and pore fluid phases $v_{r}=n \cdot\left(v_{f}-v_{s}\right)$, stiffness ratio $\chi=\frac{D}{K_{f}}, \beta=\frac{1}{n+(1-n) \cdot G_{s}}$ and $G_{s}=\frac{\rho_{s}}{\rho_{f}}$. Furthermore, $c_{w}$ is the wave velocity in the fluid, which can be expressed as $c_{w}=\sqrt{\frac{K_{f}}{\rho_{f}}}$. 


\subsection{1-D elastic wave propagation equation}

Considering a uniform soil layer of isotropic and linear visco-elastic behaviour overlying rigid bedrock, harmonic vertical motion is imposed at the bottom boundary of the soil layer. Based on Kramer (1996), vertically propagating compressional waves are generated and can be expressed by Equation (3).

$$
\begin{aligned}
v_{s}(z, t) & =A \cdot \mathrm{e}^{\mathrm{i} \cdot\left(\omega t+k^{*} \cdot z\right)} \\
k^{*} & =k \cdot(1-\mathrm{i} \cdot \xi)
\end{aligned}
$$

where $v_{s}(z, t)$ is the vertical displacement of the soil layer at depth $z$ and time $t, \omega$ is the circular frequency of the input motion, $A$ is the amplitude of the propagating wave and $k^{*}$ is the complex wave number. Based on Kramer (1996), $k^{*}$ can be expressed by the wave number $k$ ( $k=\omega / c$, where $c$ is the compressional wave velocity) and the damping ratio $\xi$, as shown in Equation (4). It should be noted that Bardet and Sayed (1993) employed a different parameter, the amplitude decay $\delta$, to quantify the wave attenuation, as expressed in Equation (5). However, the damping ratio $\xi$ is used in the present study to represent the soil material damping for compressional deformation, as this is a more widely used damping parameter in geotechnical earthquake engineering problems.

$$
\delta=\frac{c}{\xi}
$$

After substituting Equation (4) into Equation (3), the compressional wave propagation equation is expressed by Equation (6).

$$
v_{s}(z, t)=A \cdot \mathrm{e}^{\mathrm{i} \cdot \omega \cdot t+\frac{\mathrm{i} \cdot \omega \cdot z}{c}+\frac{\xi \cdot \omega \cdot z}{c}}
$$

It is convenient to introduce a complex number $\phi$ :

$$
\phi=\frac{\mathrm{i} \cdot c_{w}}{c}+\frac{\xi \cdot c_{w}}{c}
$$

from which, the compressional wave velocity and damping ratio can be expressed as:

$$
c=\frac{c_{w}}{I(\phi)} \text { and } \xi=\frac{R(\phi) \cdot c}{c_{w}}
$$


where $R(\phi)$ and $I(\phi)$ are the real and imaginary parts of complex number $\phi$ respectively.

By substituting Equation (7) into Equation (6), the compressional wave propagation equation becomes:

$$
v_{s}(z, t)=A \cdot \mathrm{e}^{\mathrm{i} \cdot \omega \cdot t+\phi \cdot \frac{\omega \cdot z}{c_{w}}}
$$

In addition, according to Bardet and Sayed (1993), the compressional wave propagation equation for the fluid phase can be expressed in a similar way, but with different amplitude $C$, as shown in Equation (10).

$$
v_{r}(z, t)=C \cdot \mathrm{e}^{\mathrm{i} \cdot \omega \cdot t+\phi \cdot \frac{\omega \cdot z}{c_{w}}}
$$

\subsection{Analytical expressions for compressional wave propagation}

After combining the elastic wave propagation equations (9) and (10) with the HM governing equation of motion (Equation (2)), two linear equations with unknowns $A$ and $C$ are obtained:

$$
\left\{\begin{array}{l}
A \cdot\left(\phi^{2} \cdot\left(\chi+\frac{1}{n}\right)+\frac{1}{\beta}\right)+C \cdot\left(1+\frac{\phi^{2}}{n}\right)=0 \\
A \cdot\left(n+\frac{\phi^{2}}{n}\right)+C \cdot\left(1+\frac{\phi^{2}}{n}-\mathrm{i} \cdot \frac{g}{k \cdot \omega}\right)=0
\end{array}\right.
$$

For a non-trivial solution, the determinant of the Equation (11) should be zero, leading to the following characteristic equation:

$$
\frac{\chi}{n} \cdot \phi^{4}+a \cdot \phi^{2}+b=0
$$

where

$$
\begin{gathered}
a=\chi+\frac{1}{n \cdot \beta}-1-\mathrm{i} \cdot \frac{g}{k \cdot \omega} \cdot\left(\chi+\frac{1}{n}\right) \\
b=\frac{1}{\beta}-n-\mathrm{i} \cdot \frac{g}{k \cdot \omega} \cdot \frac{1}{\beta}
\end{gathered}
$$

There are four complex roots for the solution of Equation (12), as expressed by 
Equation (13). These can account for the characteristics of four compressional waves, where their wave velocities and damping ratios can be calculated based on Equation (8). However, among the obtained expressions of four compressional waves, $\phi_{1}$ and $\phi_{3}$ represent the same type of wave with opposite propagation directions. Similarly, $\phi_{2}$ and $\phi_{4}$ represent another type of wave with opposite propagation directions. Therefore, two types of compressional waves (represented by $\phi_{1}$ and $\phi_{2}$ ) are introduced based on the studied HM analytical solution, which are described as the fast and slow waves respectively by Biot (1956a). Finally, the expressions of the wave velocities and damping ratios for the fast and slow waves are given by Equation (14), where subscripts 1 and 2 indicate the fast and slow waves.

$$
\begin{array}{r}
\phi_{1,3}= \pm \sqrt{\frac{-a \cdot n-\sqrt{a^{2} \cdot n^{2}-4 b \cdot n \cdot \chi}}{2 \chi}} \\
\phi_{2,4}= \pm \sqrt{\frac{-a \cdot n+\sqrt{a^{2} \cdot n^{2}-4 b \cdot n \cdot \chi}}{2 \chi}} \\
\left\{\begin{array}{l}
c_{1,2}=\frac{c_{w}}{\left|I\left(\phi_{1,2}\right)\right|} \\
\xi_{1,2}=\frac{\left|R\left(\phi_{1,2}\right)\right| \cdot c_{1,2}}{c_{w}}
\end{array}\right.
\end{array}
$$

It should be noted that the expressions of compressional wave velocities and damping ratios given by Equation (14) cannot be explicitly employed to investigate the characteristics of compressional waves, as complex parameters are involved in the expressions. Similar implicit forms of these expressions were also presented by Bardet and Sayed (1993), but employing a different damping parameter $\delta$ as mentioned in Equation (5). However, herein these expressions are mathematically solved based on the angular transformation for complex parameters, and the explicit exact solutions are derived and given by Equation (15), which extends the solutions derived by Bardet and Sayed (1993) and is believed to provide an easier way to investigate the characteristics of compressional waves. 


$$
\left\{\begin{array}{c}
c_{1,2}=\frac{c_{w}}{\left|I\left(\phi_{1,2}\right)\right|} \\
\xi_{1,2}=\frac{\left|R\left(\phi_{1,2}\right)\right| \cdot c_{1,2}}{c_{w}}
\end{array}\right.
$$

where

$$
\begin{aligned}
& \phi_{1,2}=\frac{\sqrt{r_{4}} \cdot \cos \frac{\theta_{4}}{2}}{\sqrt{2 \chi}}+i \cdot \frac{\sqrt{r_{4}} \cdot \sin \frac{\theta_{4}}{2}}{\sqrt{2 \chi}}
\end{aligned}
$$

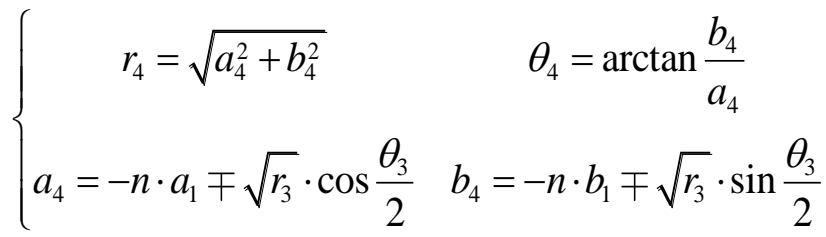

$$
\begin{aligned}
& \left\{\begin{array}{cc}
r_{3}=\sqrt{a_{3}^{2}+b_{3}^{2}} & \theta_{3}=\arctan \frac{b_{3}}{a_{3}} \\
a_{3}=n^{2} \cdot a_{1}^{2}-n^{2} \cdot b_{1}^{2}-4 n \cdot \chi \cdot a_{2} & b_{3}=2 n^{2} \cdot a_{1} \cdot b_{1}-4 n \cdot \chi \cdot b_{2}
\end{array}\right. \\
& \left\{\begin{array}{cc}
a_{1}=\chi+\frac{1}{n \cdot \beta}-1 & b_{1}=-\frac{g}{k \cdot \omega} \cdot\left(\chi+\frac{1}{n}\right) \\
a_{2}=\frac{1}{\beta}-n & b_{2}=-\frac{g}{k \cdot \omega} \cdot \frac{1}{\beta}
\end{array}\right.
\end{aligned}
$$

\subsection{Characteristics of the wave propagation velocity and damping ratio} for the fast and slow waves

By employing the expressions presented in Equation (15), the compressional wave velocities and damping ratios for the fast and slow waves can be calculated and investigated. The obtained compressional wave velocities and damping ratios are plotted in Figure 2 against the dimensionless parameter $k \omega / g$. According to Biot (1956a, b), permeability $k$ and loading frequency $\omega$ are the main parameters that affect the characteristics of compressional waves. It should be noted that the results are obtained based on typical values of soil properties, where $n=0.37$ (soil porosity) and $\rho=2.0 \mathrm{~g} / \mathrm{cm}^{3}$ (mass density). Furthermore, results of three scenarios are presented in the plots which correspond to different values of parameter $\chi$ (stiffness ratio between the soil skeleton 
constrained modulus and pore fluid bulk modulus, i.e. $\left.D / K_{f}\right)$.

Figure 2 shows the variations of the fast wave velocity and damping ratio, which are represented by the three upper lines in Figure $2 \mathrm{a}$ and three lower lines in Figure $2 \mathrm{~b}$ respectively. In particular, the following observations can be made:

- for the scenario of $\chi=0.1$ (relatively soft soil, e.g. soft clay or loose silty sand), the variation of the fast wave velocity is represented by the upper solid line in Figure $2 \mathrm{a}$. It can be seen that the fast wave velocity is independent of the ratio $k \omega / g$ in its low and high ranges (for example, approximately $<0.1$ and $>10$ respectively), but is dependent on the ratio $k \omega / g$ in its intermediate range (i.e. 0.1-10, where significant gradient changes of the wave velocity variation are mostly observed). In practical earthquake engineering applications, P-waves are assumed to be non-dispersive, while theoretically there is a limited intermediate range of $k \omega / g$ in which the $\mathrm{P}$-wave appears to be dispersive. In the high range of $k \omega / g$, the response is practically drained, dominated by the slow wave which propagates through the solid skeleton and consequently the fast wave is eliminated. Therefore the low-damping values for the fast wave in this range (Figure 2b), which is supposed to refer to both the solid and fluid phases, do not appear to have a physical meaning.

- for the scenario of $\chi=1.0$ (relatively stiff soil, e.g. stiff clay or chalk), similar trends are observed for the variations of fast wave velocity and damping ratio, compared to the previous scenario (i.e. $\chi=0.1$ ). However, larger wave velocities and smaller damping ratios are achieved, consistent with the properties of stiffer soils;

- for the scenario of $\chi=10.0$ (high stiffness soil, e.g. gravels), as expected extremely large wave velocities and almost null damping ratios are obtained for the fast wave.

The variations of wave velocity and damping ratio for the slow wave are represented by the three lower lines in Figure $2 \mathrm{a}$ and the three upper lines in Figure $2 \mathrm{~b}$ respectively. Larger slow wave velocities are observed for the stiffer soil (higher $\chi$ value), which is the same trend as the one observed for the fast wave velocity variation. Furthermore, the slow wave velocity increases, as the ratio $k \omega / g$ increases in the low range of $k \omega / g$ and stabilises in the high range of $k \omega / g$. This indicates that the slow wave becomes less dispersive as $k \omega / g$ increases. When it comes to the variation of the damping ratio for the slow wave, it can be seen that the damping ratios are considerably higher than the corresponding fast wave damping ratios in the low range of $k \omega / g$ and decrease as $k \omega / g$ 
increases. This means that the slow wave is highly attenuated in the low range of $\mathrm{k \omega} / \mathrm{g}$ and becomes less attenuated as $k \omega / g$ increases. Cleary these observations can explain why it is difficult to identify the slow wave in the low range of loading frequency, as also stated by Biot (1956a).

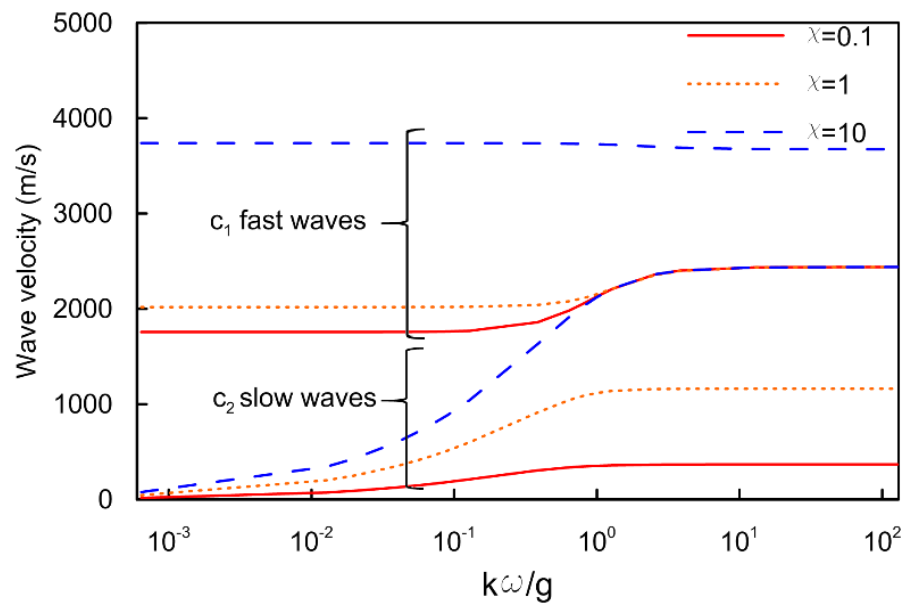

(a): Variation of compressional wave velocity

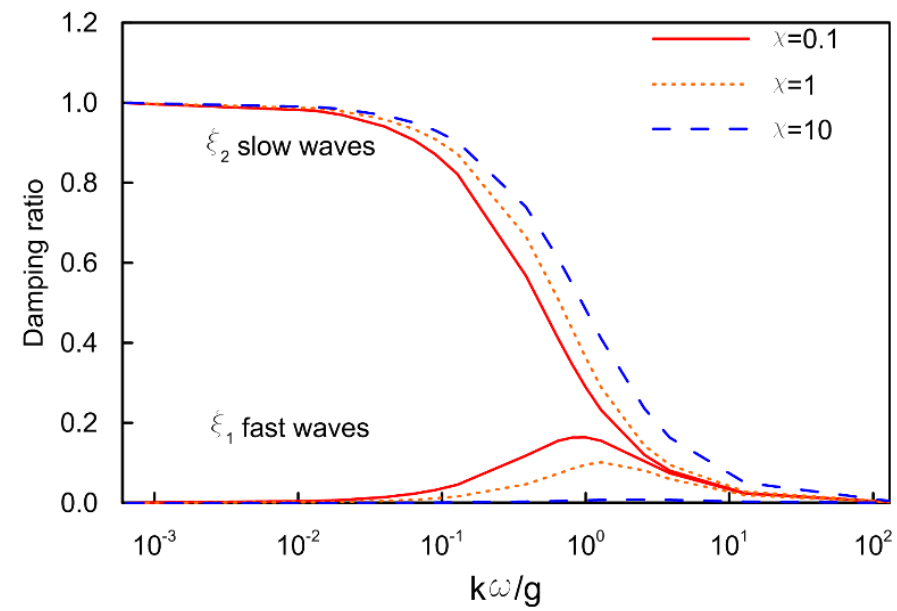

(b): Variation of compressional wave damping ratio

Figure 2: Variations of compressional wave velocity and damping ratio

\section{Numerical investigation of compressional wave propagation in saturated soils}

The results of the previously studied HM analytical solution for compressional wave propagation, showed the existence of two types of compressional waves (fast and slow waves) and indicated that their characteristics (i.e. wave dispersion and attenuation) are highly dependent on geotechnical and seismic parameters (i.e. the permeability, soil 
stiffness and loading frequency). Therefore, in this section, the compressional wave propagation mechanism is further validated and investigated by employing HM coupled FE analysis, where the influence of critical soil properties (i.e. soil permeability and soil stiffness) is explored in parametric studies.

\section{Description of numerical model}

The compressional wave propagation in a 1-D soil column is simulated employing the Imperial College Finite Element Program (ICFEP, Potts and Zdravković (1999); Kontoe (2006)), assuming linear elastic soil behaviour and plane strain geometry. The FE mesh, consisting of 800 8-noded isoparametric quadrilateral elements and the applied boundary conditions are shown in Figure 3. For the boundary conditions, the degrees of freedom (DOFs) of displacement and pore water pressure at corresponding nodes of the same height along the two vertical boundaries are tied to be identical. The pore water pressure at the top boundary is prescribed as zero and is not allowed to change throughout the analysis (i.e. $\Delta p=0$ ). The bottom boundary is considered to be impermeable (i.e. no flow across the boundary). Hydrostatic pore water pressure and static self-weight are prescribed as the initial stress for the numerical analyses, where the coefficient of earth pressure at rest $\left(K_{0}\right)$ is taken as 0.5. An absorbing viscous boundary condition (Lysmer and Kuhlemeyer, 1969) is employed at the bottom boundary, in order to absorb wave reflections.

A uniformly distributed harmonic vertical stress pulse is applied on the top boundary, with a magnitude of $10 \mathrm{kPa}$ and a duration of 0.05 second (shown in Figure 4). The employed single-frequency load $(20 \mathrm{~Hz})$ is within the range of frequencies which are relevant for the vertical motion in earthquake engineering. The dynamic load is discretised into 160 steps for the FE analysis in order to assure the accuracy of the numerical simulation. The applied load can generate compressional waves propagating from the top boundary towards the bottom boundary through the soil column. The displacement response at point A (25 m below the surface, as shown in Figure 3), is monitored for the purpose of recording the wave arrival time. The soil properties are listed in Table 1. The constant average acceleration time integration method (Newmark, 1956), is employed for the FE analysis. Neither numerical damping nor material damping are employed for this numerical simulation, in order to prevent any dissipation impact on the compressional wave propagation. In order to investigate the impact of the 
permeability on the compressional wave propagation, a parametric study is conducted for a wide permeability range. The adopted values of soil permeability are listed in Table 2, representing a reasonable range for realistic geotechnical materials as shown in Table 3. Furthermore, based on Table 2, although only a single-frequency load is employed, the resulting $k \omega / g$ values of the parametric study cover the usual range of $k \omega / g$ for a variety of soil dynamics problems shown in Table 3. Finally, the u-p formulation is employed for the HM consolidation formulation of ICFEP, while the examined HM analytical solution for the compressional wave propagation is based on the $\mathrm{u}-\mathrm{U}$ formulation. However, according to Schanz and Pryl (2004), the $\mathrm{u}-\mathrm{U}$ formulation is supposed to possess the same roots as the $u-p$ formulation, where, as it was mentioned before, the roots represent the solutions for the compressional waves.

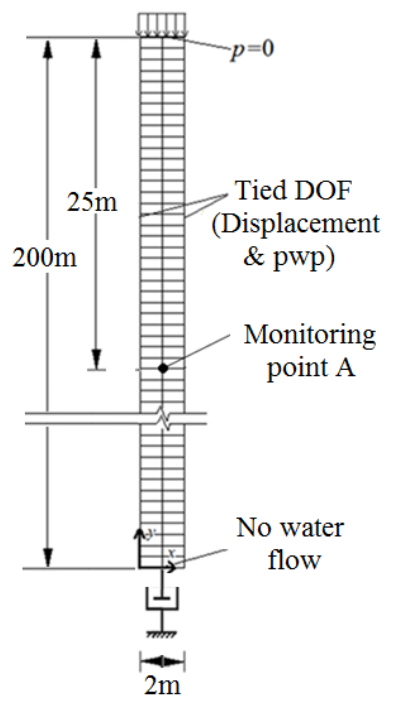

Figure 3: A schematic graph for the FE model in coupled analysis

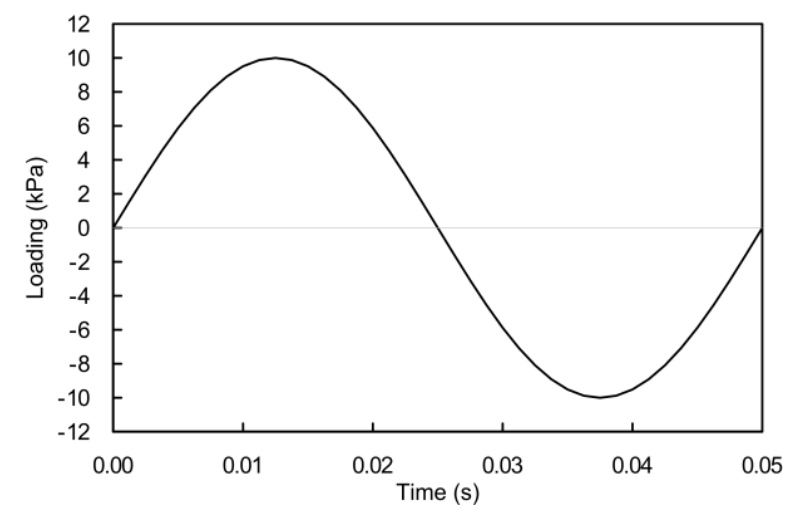

Figure 4: Input vertical motion for the coupled 1-D column FE analysis 
Table 1: Soil properties of the coupled 1-D column FE analysis

\begin{tabular}{|c|c|}
\hline Parameter & Value \\
\hline Young's modulus E $(\mathrm{kPa})$ & $1.98 \mathrm{E}+05(\chi=0.1)$ \\
\hline Constrained modulus $\mathrm{D}(\mathrm{kPa})$ & $2.20 \mathrm{E}+05(\chi=0.1)$ \\
\hline Bulk modulus of fluid $\mathrm{K}_{\mathrm{f}}(\mathrm{kPa})$ & $2.20 \mathrm{E}+06$ \\
\hline Stiffness ratio $\chi$ & 0.1 \\
\hline Density $\rho\left(\mathrm{g} / \mathrm{cm}^{3}\right)$ & 2.0 \\
\hline Poisson's ratio $v$ & 0.2 \\
\hline Porosity n & 0.37 \\
\hline
\end{tabular}

Table 2: Detailed soil properties for seven cases $(\chi=0.1)$

\begin{tabular}{|c|c|c|c|c|c|c|c|}
\hline Parameter $(\boldsymbol{\chi}=\mathbf{0 . 1})$ & Case1 & Case2 & Case3 & Case4 & Case5 & Case6 & Case7 \\
\hline Permeability k $(\mathrm{m} / \mathrm{s})$ & $1.0 \mathrm{E}-7$ & $1.0 \mathrm{E}-3$ & $3.0 \mathrm{E}-2$ & $5.0 \mathrm{E}-2$ & $1.0 \mathrm{E}-1$ & $1.0 \mathrm{E}+1$ & $1.0 \mathrm{E}+2$ \\
\hline $\mathrm{k} \omega / \mathrm{g}$ & $\mathbf{1 . 0 E - 6}$ & $\mathbf{0 . 0 1}$ & $\mathbf{0 . 3 8}$ & $\mathbf{0 . 6 4}$ & $\mathbf{1 . 2 8}$ & $\mathbf{1 2 8 . 0}$ & $\mathbf{1 2 8 0 . 0}$ \\
\hline
\end{tabular}

Table 3: Parameter range of $k \omega / g$ for a variety of soil dynamics problems

\begin{tabular}{|c|c|c|c|c|c|c|c|c|c|c|c|c|}
\hline & & & \multicolumn{10}{|c|}{ Permeability ranges for geotechnical materials $(k=m / s)(F e t t e r, 1994)$} \\
\hline \multirow{2}{*}{\multicolumn{3}{|c|}{$k \omega / g$}} & \multicolumn{2}{|c|}{ Clay } & \multicolumn{2}{|c|}{$\begin{array}{l}\text { Silt, clayey } \\
\text { sands, Silty } \\
\text { sands, fine } \\
\text { sands } \\
\end{array}$} & \multicolumn{2}{|c|}{$\begin{array}{l}\text { Well-sorted } \\
\text { sands, glacial } \\
\text { outwash }\end{array}$} & \multicolumn{2}{|c|}{$\begin{array}{c}\text { Well-sorted } \\
\text { gravel }\end{array}$} & \multicolumn{2}{|c|}{$\begin{array}{c}\text { Rockfill } \\
\text { materials }\end{array}$} \\
\hline & & & $1 E-11$ & $1 E-08$ & $1 E-08$ & $1 E-05$ & $1 E-05$ & $1 E-03$ & $1 E-04$ & $1 E-02$ & $1 E-01$ & $1 E+01$ \\
\hline \multirow{2}{*}{ •气 } & \multirow{2}{*}{ Storm } & 0.01 & $6.4 \mathrm{E}-14$ & $6.4 \mathrm{E}-11$ & $6.4 \mathrm{E}-11$ & $6.4 \mathrm{E}-08$ & $6.4 \mathrm{E}-08$ & $6.4 \mathrm{E}-06$ & $6.4 \mathrm{E}-07$ & $6.4 \mathrm{E}-05$ & $6.4 \mathrm{E}-04$ & $6.4 \mathrm{E}-02$ \\
\hline & & 0.1 & $6.4 \mathrm{E}-13$ & $6.4 \mathrm{E}-10$ & $6.4 \mathrm{E}-10$ & $6.4 \mathrm{E}-07$ & $6.4 \mathrm{E}-07$ & $6.4 \mathrm{E}-05$ & $6.4 \mathrm{E}-06$ & $6.4 \mathrm{E}-04$ & $6.4 \mathrm{E}-03$ & $6.4 \mathrm{E}-01$ \\
\hline 象 & \multirow{2}{*}{$\begin{array}{l}\text { Ocean } \\
\text { waves }\end{array}$} & 0.05 & $3.2 \mathrm{E}-13$ & $3.2 \mathrm{E}-10$ & $3.2 \mathrm{E}-10$ & $3.2 \mathrm{E}-07$ & $3.2 \mathrm{E}-07$ & $3.2 \mathrm{E}-05$ & $3.2 \mathrm{E}-06$ & $3.2 \mathrm{E}-04$ & $3.2 \mathrm{E}-03$ & 3.2E-01 \\
\hline 仓ै & & 0.14 & $9.0 \mathrm{E}-13$ & $9.0 \mathrm{E}-10$ & $9.0 \mathrm{E}-10$ & $9.0 \mathrm{E}-07$ & $9.0 \mathrm{E}-07$ & $9.0 \mathrm{E}-05$ & $9.0 \mathrm{E}-06$ & $9.0 \mathrm{E}-04$ & $9.0 \mathrm{E}-03$ & $9.0 \mathrm{E}-01$ \\
\hline$\stackrel{0}{*}$ & \multirow{2}{*}{$\begin{array}{c}\text { Traffic and } \\
\text { seismic } \\
\text { loading }\end{array}$} & 1 & $6.4 \mathrm{E}-12$ & $6.4 \mathrm{E}-09$ & $6.4 \mathrm{E}-09$ & $6.4 \mathrm{E}-06$ & $6.4 \mathrm{E}-06$ & $6.4 \mathrm{E}-04$ & $6.4 \mathrm{E}-05$ & $6.4 \mathrm{E}-03$ & $6.4 \mathrm{E}-02$ & $6.4 \mathrm{E}+00$ \\
\hline 룽 품 & & 30 & $1.9 \mathrm{E}-10$ & $1.9 \mathrm{E}-07$ & $1.9 \mathrm{E}-07$ & $1.9 \mathrm{E}-04$ & $1.9 \mathrm{E}-04$ & $1.9 \mathrm{E}-02$ & $1.9 \mathrm{E}-03$ & $1.9 \mathrm{E}-01$ & $1.9 \mathrm{E}+00$ & $1.9 \mathrm{E}+02$ \\
\hline \multirow{2}{*}{ 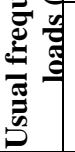 } & \multirow{2}{*}{$\begin{array}{c}\text { Machine } \\
\text { foundations }\end{array}$} & 10 & $6.4 \mathrm{E}-11$ & $6.4 \mathrm{E}-08$ & $6.4 \mathrm{E}-08$ & $6.4 \mathrm{E}-05$ & $6.4 \mathrm{E}-05$ & $6.4 \mathrm{E}-03$ & $6.4 \mathrm{E}-04$ & $6.4 \mathrm{E}-02$ & $6.4 \mathrm{E}-01$ & $6.4 \mathrm{E}+01$ \\
\hline & & 100 & $6.4 \mathrm{E}-10$ & $6.4 \mathrm{E}-07$ & $6.4 \mathrm{E}-07$ & $6.4 \mathrm{E}-04$ & $6.4 \mathrm{E}-04$ & 6.4E-02 & $6.4 \mathrm{E}-03$ & $6.4 \mathrm{E}-01$ & $6.4 \mathrm{E}+00$ & $6.4 \mathrm{E}+02$ \\
\hline
\end{tabular}

\section{Compressional wave propagation mechanism}

The displacement time histories at the monitoring point $\mathrm{A}$ for the seven studied cases are compared in Figure 5. When a relatively low permeability is employed for the soil 
column (case1 and case2), identical results are observed, as for these cases only one type of compressional wave exists, which is the well-recognised fast wave. For a low permeability soil, the solid and the pore fluid move in-phase and therefore the fast wave dominates in this scenario. When higher permeability is considered (case3), the fast wave still dominates the propagating mechanism, but with a lower wave amplitude compared to the previous cases. By further increasing the soil permeability (case4), another compressional wave appears after the fast wave. When continuing to increase the permeability (case5), the fast wave amplitude gradually decreases, while the slower compressional wave amplitude increases. However, for the case in which considerably high permeability (case6) is employed, the fast wave is strongly attenuated and almost disappears, while the slower compressional wave becomes the dominant wave. Finally, from case 6 to case 7, the slower compressional wave amplitude stabilises.

In order to further investigate the two observed compressional waves, the wave velocities monitored at point $\mathrm{A}$ in the $\mathrm{FE}$ analysis are compared to the ones obtained from the analytical solution in Figure 6. The numerically obtained wave velocities are calculated by dividing the distance between the monitoring point $\mathrm{A}$ and the top boundary by the different wave arrival times. It shows that the wave velocities from the low-permeability FE analyses match with the fast wave velocities from the analytical solution, indicating that the fast wave dominates the low permeability range (i.e. smaller than $5.0 \mathrm{E}-2 \mathrm{~m} / \mathrm{s})$. In the same figure, the velocities of the observed slower compressional wave from the high-permeability FE analyses agree reasonably well with the analytically derived slow wave velocities. This agreement is not only observed for the investigated case of employing a usual porosity $n=0.37$, but also for a considerably wide porosity range ( $n=0.1-0.7$ shown as the three dash lines in Figure 6), where the dependency of the slow wave velocity on material porosity is very limited. Therefore, the computed slower compressional wave can probably be attributed to the compressional wave of the second kind, the slow wave, which is observed to dominate the high permeability range (i.e. larger than $5.0 \mathrm{E}-2 \mathrm{~m} / \mathrm{s}$ ).

As mentioned before, the existence of the slow wave proposed by Biot in 1956 has been both experimentally and numerically proved by researchers, but mostly for ultrasonic-frequency loading, which is beyond the relevant frequency range for geotechnical earthquake engineering problems. The present work numerically shows the transition from the fast wave to the slow wave with the aid of HM coupled FE analysis 
of a soil column, considering the impact of soil permeability. Different dominant permeability ranges for the two types of compressional waves can be distinguished; the fast wave dominates the low permeability range (i.e. smaller than $5.0 \mathrm{E}-2 \mathrm{~m} / \mathrm{s}$ ) and the slow wave dominates the high permeability range (i.e. larger than $5.0 \mathrm{E}-2 \mathrm{~m} / \mathrm{s}$ ).

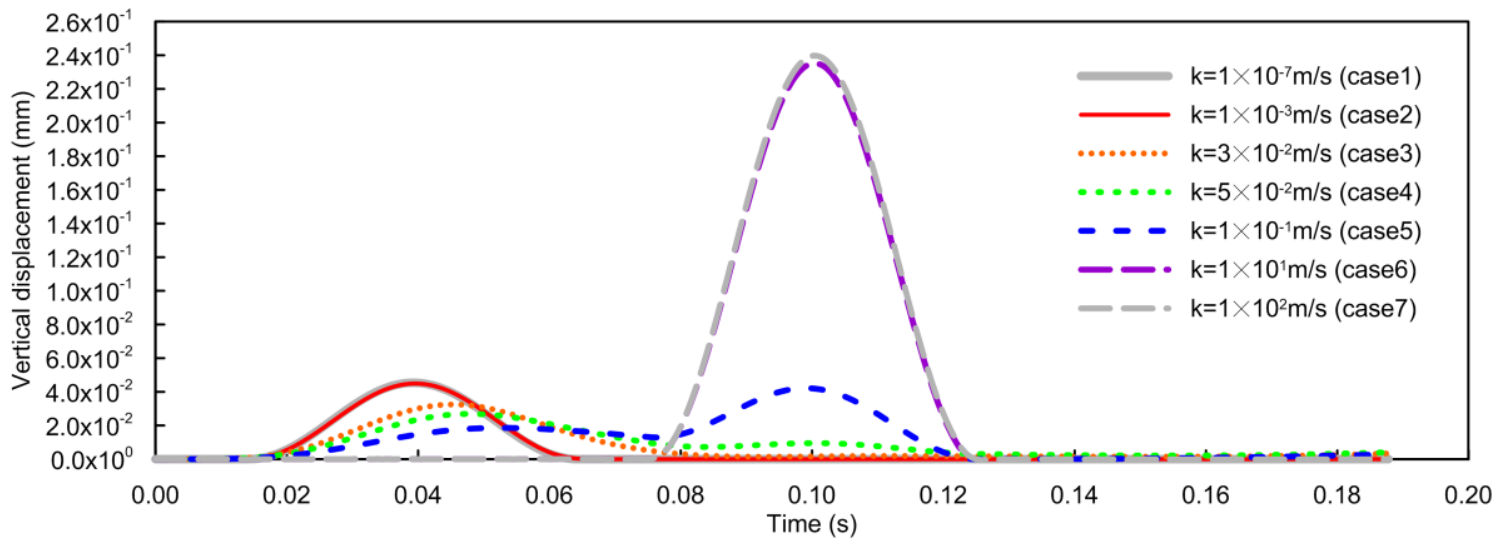

Figure 5: Displacement time histories at monitoring point A for the seven permeability cases $(\chi=0.1)$

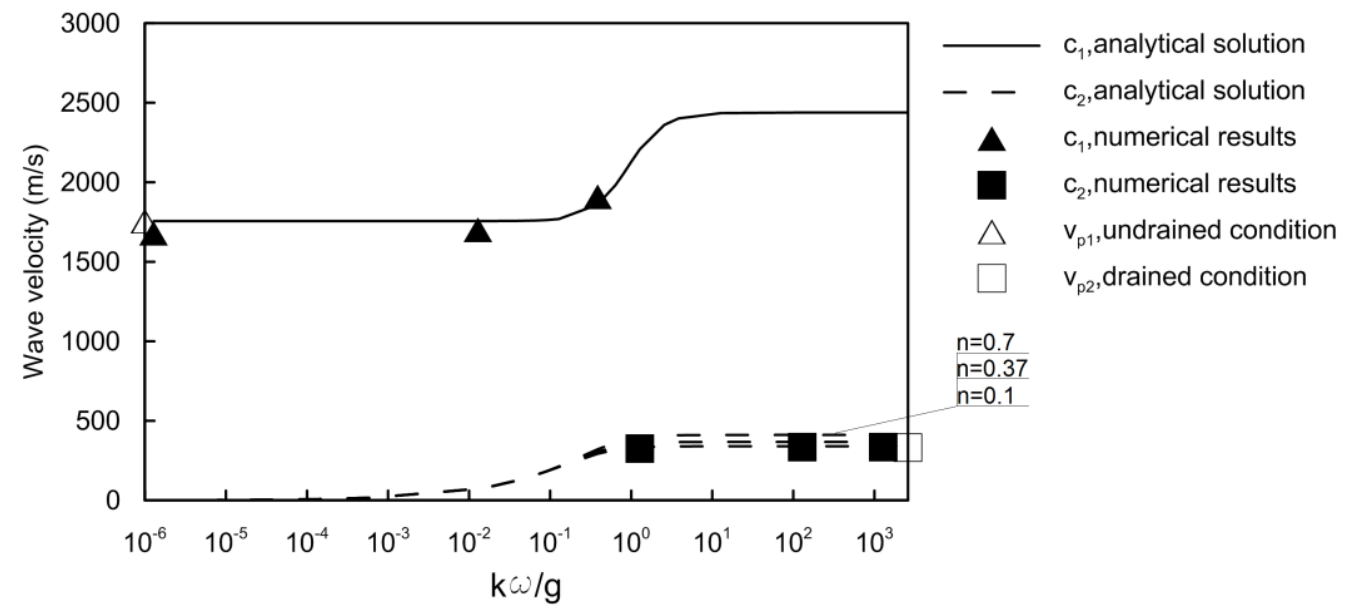

Figure 6: Comparison of compressional wave velocity between analytical and numerical results $(\chi=0.1)$

\section{Compressional wave attenuation}

The transition from the fast wave to the slow wave can be explained by the characteristics of the damping ratio of the compressional waves. As observed in Figure 5 for $\chi=0.1$, the amplitude of the fast wave gradually decreases as permeability increases and it finally vanishes. The fast wave dominates the response in the low permeability range for which the corresponding damping ratio is low (see Figure $2 \mathrm{~b}$ ) and gradually phases out with a corresponding increase in damping ratio. Eventually for high 
permeability values, the response is drained and the fast wave is completely eliminated (despite the low damping values as explained earlier). On the other hand, the slow wave is absent in the low permeability range, while its amplitude is gradually raised with increasing permeability. This means that the slow wave becomes less attenuated as permeability increases, which is in agreement with the variation of the damping ratio for the slow wave shown in Figure $2 b$.

\section{Physical meaning of the two compressional waves}

Figure 6 additionally compares the wave velocities obtained by the FE analysis with the analytically calculated compressional wave velocities under two extreme soil state conditions (undrained and drained conditions), based on the Zienkiewicz et al. (1980) solution shown in Equation (16). The calculated wave velocities for the undrained and drained conditions are plotted at the ends of the $k \omega / g$ axis, in order to represent the two extreme conditions. It should be noted that the notation $v_{p}$ is employed to express the compressional wave velocities for the undrained and drained conditions derived from a one-phase study, in order to distinguish it from parameter $c$ which is used for the HM coupled solutions. It can be observed that the compressional wave velocities from numerical and analytical solutions for extremely high and low permeability values approach the compressional wave velocities under drained and undrained conditions respectively. Consequently, for the compressional wave propagation in low permeability soils or under undrained conditions, the solid and pore fluid move in-phase and therefore the fast wave dominates the response. For high permeability soils or under drained conditions, the slow wave dominates the response due to the out-of-phase movement between the solid and fluid phases. Furthermore, these results also highlight

the importance of employing HM coupled formulation to accurately simulate the compressional wave propagation at intermediate transient states between the undrained and drained conditions.

$$
\begin{gathered}
v_{p 1}=\sqrt{\left(\frac{E(1-v)}{(1+v)(1-2 v)}+\frac{K_{f}}{n}\right) / \rho} \\
v_{p 2}=\sqrt{\frac{E(1-v)}{(1+v)(1-2 v)} / \rho}
\end{gathered}
$$




\section{Effect of stiffness ratio on the compressional wave propagation}

In order to further investigate the HM compressional wave propagation mechanism, a parametric study is conducted to examine the impact of the stiffness ratio between the soil skeleton constrained modulus and pore fluid bulk modulus $(\chi)$. Two scenarios are considered, by employing values of $\chi$ as 1.0 and 10.0, where the corresponding constrained moduli are $2.20 \mathrm{E}+06 \mathrm{kPa}$ and $2.20 \mathrm{E}+07 \mathrm{kPa}$ respectively. The remaining soil properties are the same as those used in the previous section (shown in Tables 1 and 2).

The displacement time histories at monitoring point A for seven cases are compared in Figure 7 for the scenario of $\chi=1.0$. From case 1 to case 7 , as an increasingly higher permeability is employed, the same trend is observed as for the wave propagation mechanism previously observed for the scenario $\chi=0.1$ in Figure 5 . In particular, the numerically simulated fast wave is observed to gradually transit to the slow wave, as the two waves dominate the response in different permeability ranges. However, the fast and slow wave fronts are much closer and sometimes overlap with each other, compared to the results for the scenario of $\chi=0.1$. This can be explained considering Figure 8 which shows that the differences between the fast and slow wave velocities are smaller for the scenario of $\chi=1.0$. In Figure 8, compressional wave velocities calculated from the FE analysis are compared with the ones obtained from the analytical solution and from Zienkiewicz et al. (1980b) for undrained and drained conditions. A good agreement is observed between the numerically and analytically obtained wave velocities.

For the scenario of $\chi=10.0$, the displacement time histories at the monitoring point $\mathrm{A}$ and the corresponding wave velocity comparison are shown in Figures 9 and 10 respectively. Based on Figure 9, only one compressional wave is observed for the different permeability cases. Indeed, Figure 10 shows all the numerically derived wave velocities are approximately identical and agree with the fast wave velocities from the analytical solution. Furthermore, the wave velocities under undrained and drained conditions are also very similar and match the numerically obtained wave velocities. This is due to the insignificant impact of pore-fluid bulk modulus on the wave velocities for the scenario of high $\chi$ value, which can be also depicted from Zienkiewicz et al.'s theory (Equation (16)). As the slow wave only exists when the solid and pore fluid move out-of-phase, when a high stiffness ratio is employed for the soil, the interaction effect between the solid and pore fluid is negligible, and therefore the slow wave is 
highly attenuated and only the fast wave exists.

The parametric study for the stiffness ratio impact on the compressional wave propagation mechanism shows that when relatively low $\chi$ values are considered for the soil layer, the fast and slow wave dominate different permeability ranges and a transition from the fast wave to the slow wave is observed. When relatively high $\chi$ values are considered for the soil layer, only the fast wave exists, due to the insignificant interaction effect between the solid and pore fluid phases.

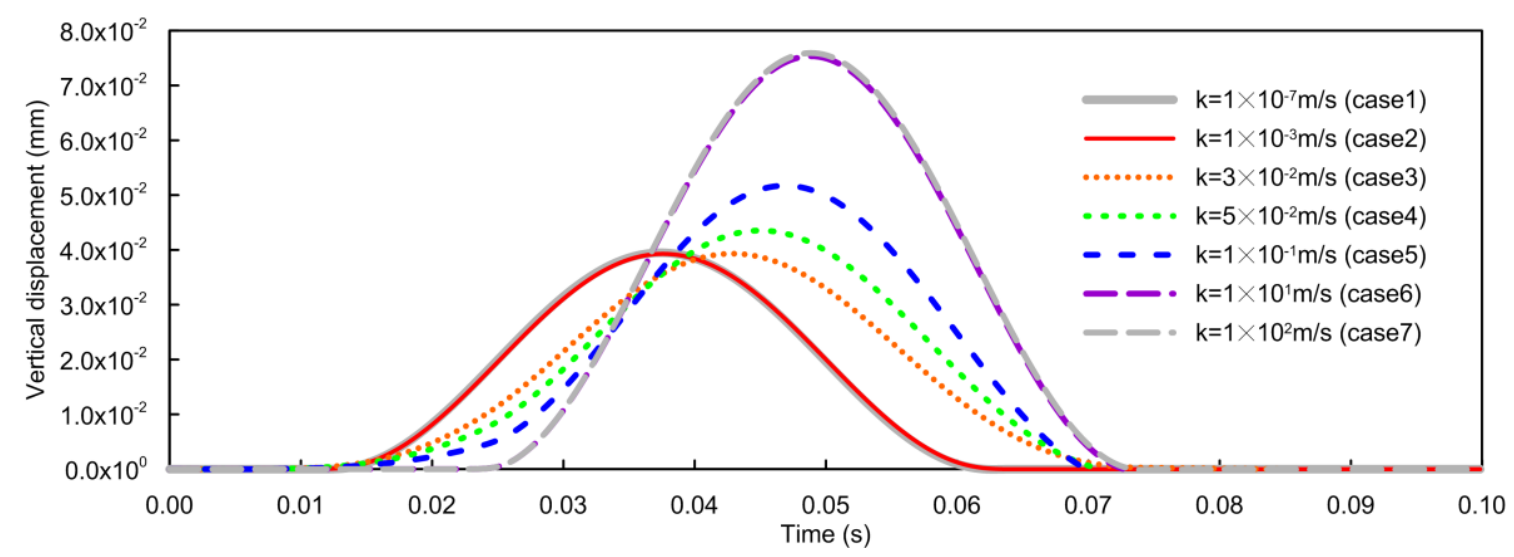

Figure 7: Displacement time histories at monitoring point $\mathrm{A}$ for seven cases $(\chi=1.0)$

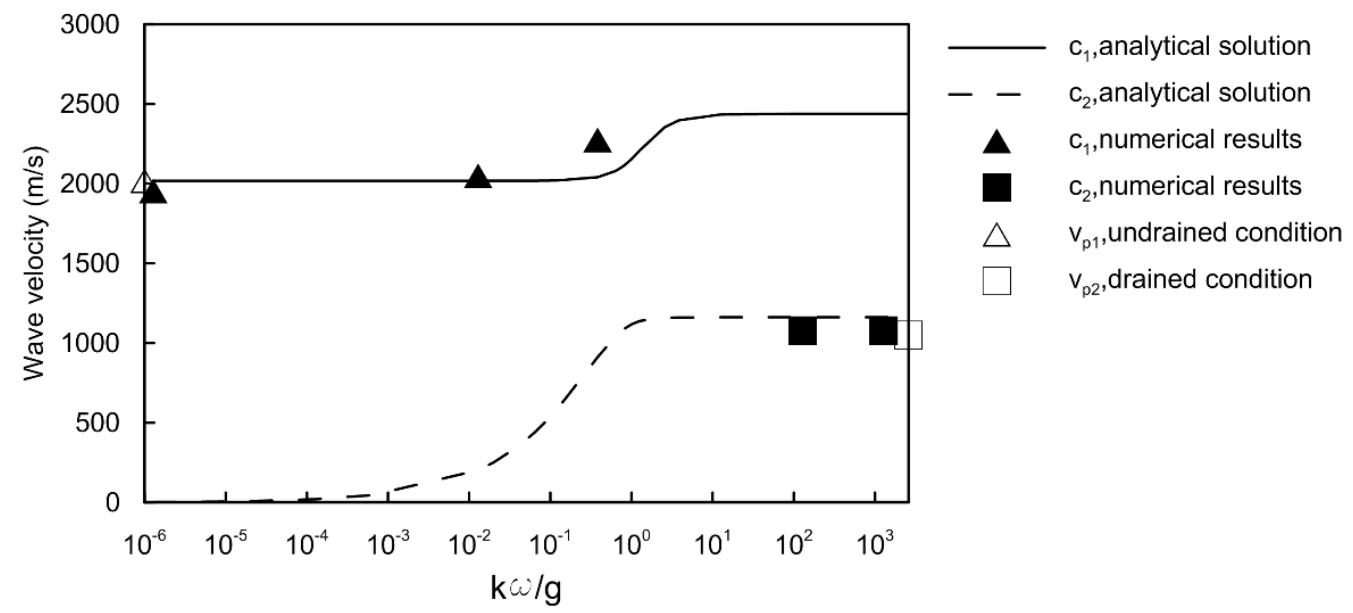

Figure 8: Comparison of compressional wave velocity $(\chi=1.0)$ 


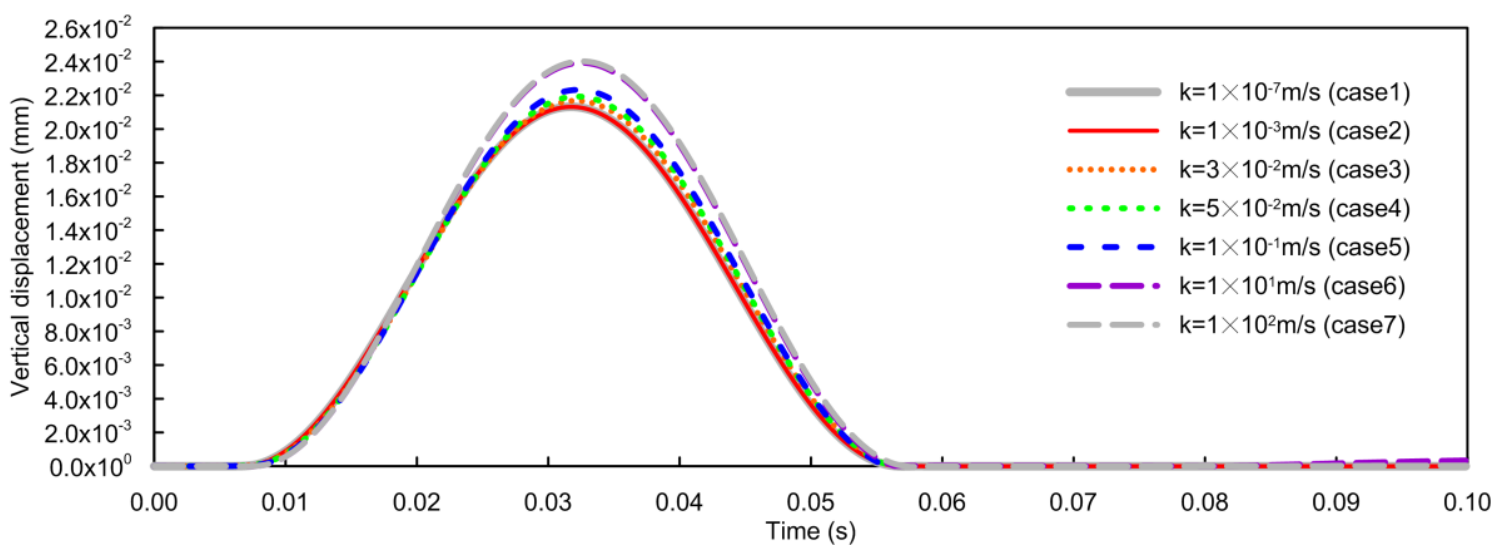

Figure 9: Displacement time histories at monitoring point A for seven cases $(\chi=10.0)$

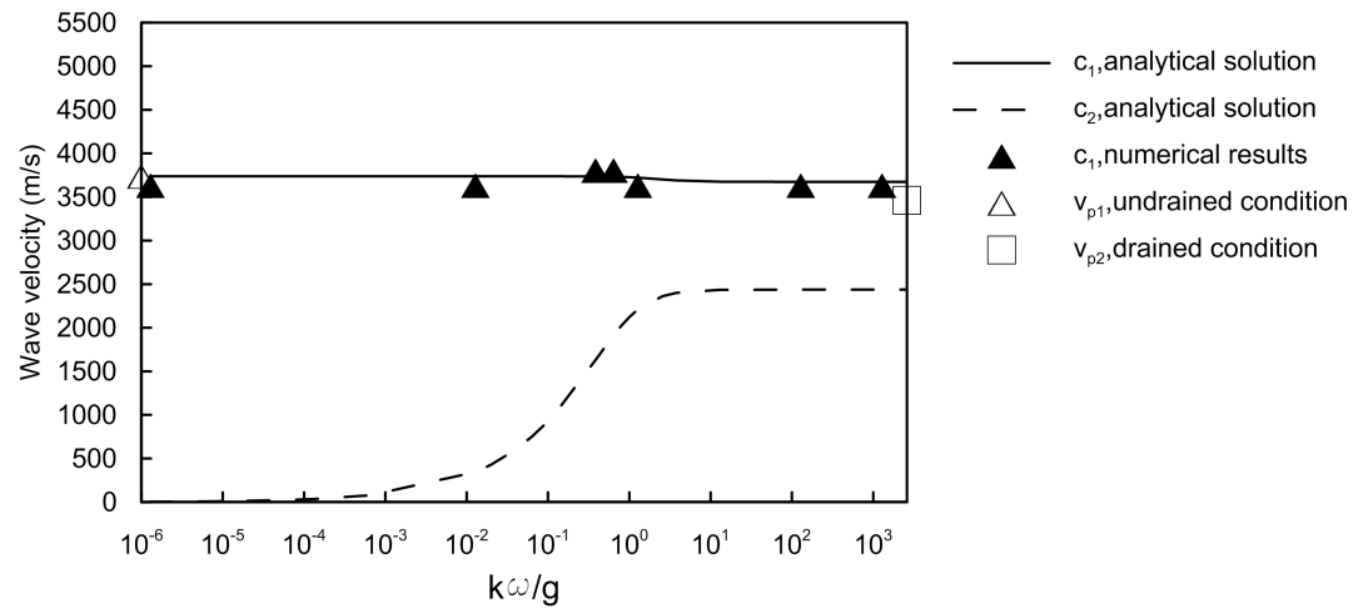

Figure 10: Comparison of compressional wave velocity $(\chi=10.0)$

\section{Conclusions}

This paper investigates the compressional wave propagation mechanism in saturated soils employing hydro-mechanically (HM) coupled analytical and numerical methods. The findings of this study aid the understanding of compressional dynamic soil behaviour and of the dynamic response of geotechnical structures to vertical components of the ground motion. In particular, the following conclusions can be drawn:

- A HM analytical solution for compressional wave propagation was first studied. The exact explicit solutions for the dispersion and attenuation characteristics of compressional waves were derived, by combining the elastic wave propagation equation with the HM coupled governing equation of motion for saturated porous 
materials. Based on the derived solution, the characteristics of compressional waves were parametrically investigated, showing the existence of two types of compressional waves (the fast and slow waves) and indicating that their characteristics (i.e. the wave dispersion and attenuation) are highly dependent on critical geotechnical and seismic parameters (i.e. permeability, soil stiffness and loading frequency).

- The compressional wave propagation mechanism was then rigorously simulated and investigated by $\mathrm{HM}$ coupled FE analysis. The numerical study predicted the transition from the fast wave to a slower compressional wave by considering the impact of soil permeability. This slower compressional wave can probably be attributed to the compressional wave of the second kind (the slow wave) due to their wave velocity agreement. Furthermore, the numerical study highlighted the different dominant permeability ranges of the two types of compressional waves, where in particular, the fast wave dominates the low permeability range (i.e. approximately smaller than $5.0 \mathrm{E}-2 \mathrm{~m} / \mathrm{s}$ ) and the slow wave dominates the high permeability range (i.e. approximately larger than $5.0 \mathrm{E}-2 \mathrm{~m} / \mathrm{s}$ ). A transition from the fast wave to the slow wave was observed when an increasingly higher permeability was employed for the HM coupled FE analysis of a soil column. The corresponding transition point, in terms of the dimensionless parameter $k \omega / g$, is approximately at 0.64 . However, when relatively high stiffness ratios $\chi$ were considered for the soil layer, only the fast wave existed, due to the insignificant interaction between the solid and pore fluid components for that case.

- The numerically simulated compressional wave propagation mechanism under different permeability ranges, was shown to be consistent with the theoretical dispersion and attenuation characteristics of fast and slow waves.

- For engineering practice, the coupled FE analysis shows the existence of the slow compression wave for a range of permeability and loading frequency that is relevant for geotechnical earthquake engineering applications. In particular, the identified dominant permeability range for the slow wave is observed approximately above $5.0 \mathrm{E}-2 \mathrm{~m} / \mathrm{s}$, which is practically relevant to gravelly or rockfill materials employed in embankment dam constructions. It is therefore suggested that coupled consolidation analysis is necessary to accurately account for the effects of soil permeability on the dynamic soil properties of such geotechnical materials (i.e. P-wave velocities and damping ratios) and for the dynamic response of geotechnical structures to vertical 
ground motion at intermediate transient states between undrained and drained conditions.

- Although the FE method and the analytical solution are shown to both predict well the characteristics of the compressional waves in the elastic domain, HM coupled numerical analysis, in combination with appropriate constitutive models, is the only tool that can realistically simulate inelastic soil behaviour in dynamic boundary value problems.

\section{References}

Arntsen, B. and Carcione, J. M. (2001). Numerical simulation of the Biot slow wave in water-saturated Nivelsteiner Sandstone. Geophysics, 66(3): 890-896.

Bardet, J. P. and Sayed, H. (1993). Velocity and attenuation of compressional waves in nearly saturated soils. Soil Dynamics and Earthquake Engineering, 12(7): 391-401.

Berryman, J. G. (1980). Confirmation of Biot' theory. Applied Physics Letters, 37(4): 382-384.

Biot, M. A. (1956a). Theory of propagation of elastic waves in a fluid saturated porous solid 1: Lowfrequency range. Journal of the Acoustical Society of America, 28(2): 168-178.

Biot, M. A. (1956b). Theory of propagation of elastic waves in a fluid saturated porous solid 2: Higherfrequency range. Journal of the Acoustical Society of America, 28(2): 179-191.

Boyle, F. A. and Chotiros, N. P. (1991). Experimental detection of a slow acoustic wave in sediment at shallow grazing angles. Journal of Acoustical Society of America, 91(5): 2615-2619.

Bradley, B. A. (2011). Near-source strong ground motions observed in the 22 February 2011 Christchurch earthquake. Seismological Research Letters, 82(6): 853-865.

Dutta, N. C. (1980). Theoretical analysis of observed second bulk compressional wave in a fluid saturated porous solid at ultrasonic frequencies. Applied Physics Letters, 37(10): 898-900.

Fetter, C. W. (1994). Applied Hydrogeology, 3rd ed. Upper Saddle River, NJ: Prentice Hall, Inc.

Gu, J. and Zhao, Z. (2009). Considerations of the discontinous deformation analysis on wave propagation problems. International journal for Numerical and Analytical Methods in Geomechanics, 33: $1449-1465$.

Gurevich, B., Kelder, O. and Smeulders, D. M. J. (1999). Validation of the slow compressional wave in porous media comparison of experiments and numerical simulations. Transport in Porous Media, 36(2): 149-160.

Kelder, O. and Smeulders, D. M. J. (1997). Observation of the Biot slow wave in water-saturated Nivelsteiner Sandstone. Geophysics, 62: 1794-1796. 
Kim, S. H., Kim, K. J. and Blouin, S. E. (2002). Analysis of wave propagation in saturated porous media. I. Theoretical solution. Computer Methods in Applied Mechanics and Engineering, 191: 40614073.

Kontoe, S. (2006). Development of time integration schemes and advanced boundary conditions for dynamic geotechnical analysis. PhD thesis, Imperial College London.

Kramer, S. L. (1996). Geotechnical earthquake engineering. New Jersey: Prentice Hall.

Kunnath, S. K., Erduran, E., Chai, Y. H. and Yashinsky, M. (2008). Effect of near-fault vertical ground motions on seismic response of highway overcrossings. Journal of Bridge Engineering, ASCE, 13: 282-290.

Lee, R. L., Bradley, B. A. and Franklin, M. J. (2013). Characteristics of vertical ground motions in the Canterbury earthquakes. 2013 New Zealand Society of Earthquake Engineering Technical Conference and AGM.

Lysmer, J. and Kuhlemeyer, R. L. (1969). Finite dynamic model for infinite media. Journal of the Engineering Mechanics Division, ASCE, 95(4): 859-877.

Meng, J., and Rix, G. J. (2004). Measurement of strain rate effects on dynamic soil properties. Advances in geotechnical engineering: the Skempton conference, Thomas Telford, 1: 441-452.

Nagy, P. B., Alder, L. and Bonner, B. P. (1990). Slow wave propagation in airfilled porous materials and natural rocks. Applied Physics Letters, 56(25): 2504-2506.

Newmark, N. M. (1959). A method of computation for structural dynamics. Journal of Engineering Mechanics, ASCE, 85: 67-94.

Papazoglou, A. J. and Elnashai, A. S. (1996). Analytical and field evidence of the damaging effect of vertical earthquake ground motion. Earthquake Engineering and Structural Dynamics, 25(2): 1109-1137.

Plona, T. J. (1980). Observation of a second bulk compressional wave in a porous medium at ultrasonic frequencies. Applied Physics Letters, 36(4): 259.

Potts, D. M. and Zdravkovic, L. (1999). Finite element analysis in geotechnical engineering: Theory. London: Thomas Telford.

Rasolofosaon, P. N. J. (1988). Importance of interface hydraulic condition on the generation of second bulk compressional wave in porous media. Applied Physics Letters, 52(10): 780-782.

Riches, L. K. (2015). Observed Earthquake Damage to Christchurch City Council Owned Retaining Walls and the Repair Solutions Developed. Proceeding of the 6th International Conference on Earthquake Geotechnical Engineering 2015, Christchurch, New Zealand.

Schanz, M. and Pryl, D. (2004). Dynamic fundamental solutions for compressible and incompressible modeled poroelastic continua. International Journal of Solids and Structures, 41(15): 4047-4073. 
Teng, Y. (1990). Finite element results of the slow compressional wave in a porous medium at ultrasonic frequencies. Applied Physics Letters, 68(8): 4335-4337.

Wu, J.H. (2010). Seismic Landslide Simulations in Discontinuous Deformation Analysis. Computers and Geotechnics, 37(5): 594-601.

Yang, J. and Sato, T. (2000). Interpretation of seismic vertical amplification observed at an array site. Bulletin of the Seismological Society of America, 90(2): 275-285.

Yang, J. and Yan, X. R. (2009). Factors affecting site response to multi-directional earthquake loading. Engineering Geology, 107(3-4): 77-87.

Zienkiewicz, O. C., Chang, C. T. and Bettess, P. (1980). Drained, undrained, consolidating and dynamic behaviour assumptions in soils. Geotechnique, 30(4): 385-395. 


\section{Notation (SI units):}

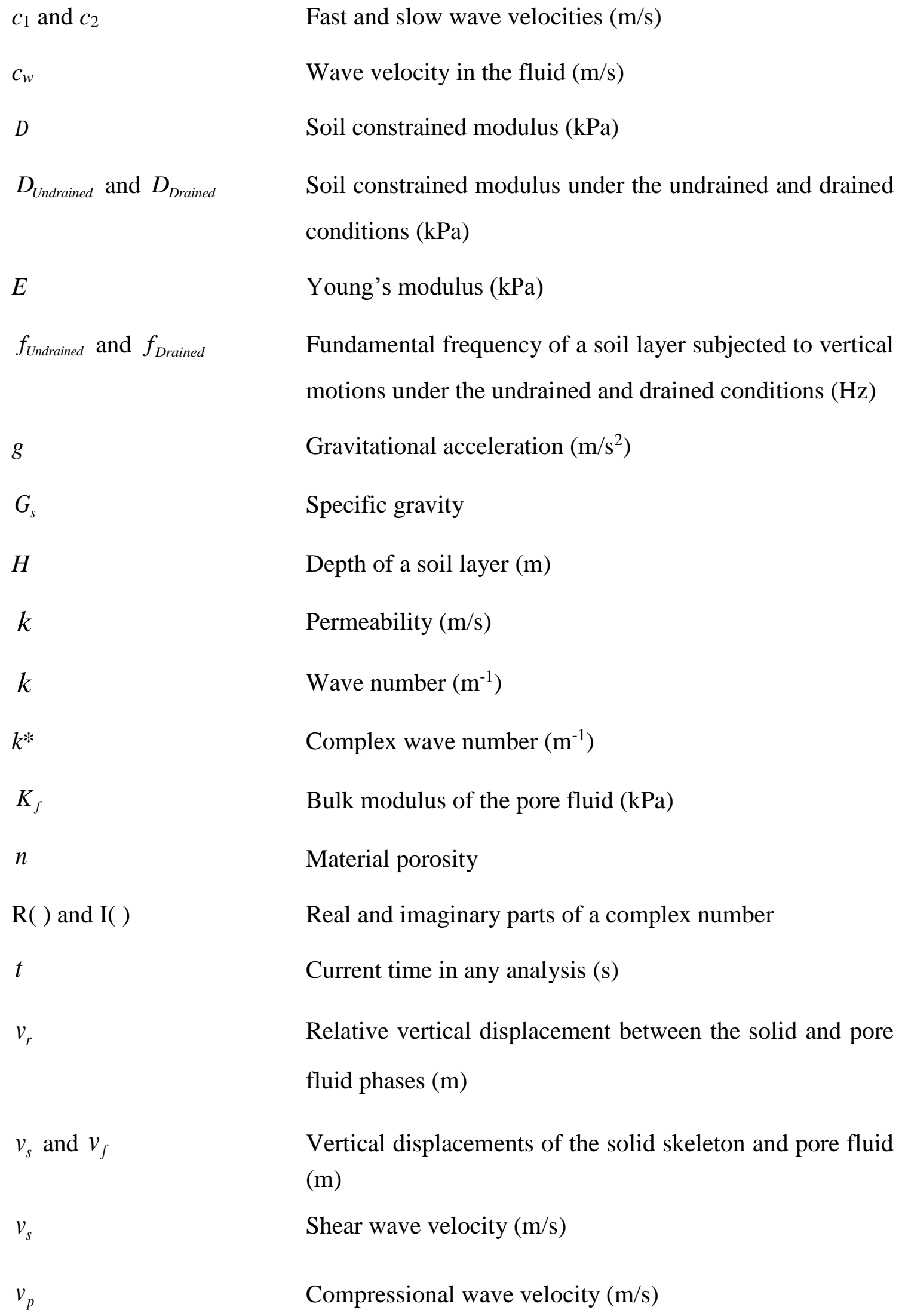


$v_{\text {pUndrained }}$ and $v_{\text {pDrained }}$

$z$

$\delta$

$v$

$\xi$

$\xi_{1}$ and $\xi_{2}$

$\rho_{s}$ and $\rho_{f}$

$\phi$

$\chi$

$\omega$
Compressional wave velocity under the undrained and drained conditions $(\mathrm{m} / \mathrm{s})$

Vertical distance in a soil layer from the coordinate origin (m)

Amplitude decay employed by to quantify the wave attenuation in Bardet and Sayed (1993)

Poisson's ratio

Material damping ratio

Damping ratios for fast and slow waves

Densities of the solid skeleton and pore fluid $\left(\mathrm{g} / \mathrm{cm}^{3}\right)$

A complex number representing different types of compressional waves

Ratio between the effective soil constrained modulus and pore fluid bulk modulus

Circular frequency of an input motion ( $\mathrm{rad} / \mathrm{s})$ 